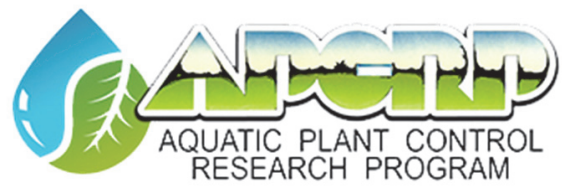

\title{
Evaluating Drone Truthing as an Alternative to Ground Truthing: An Example with Wetland Plant Identification
}

by Glenn M. Suir, Christina L. Saltus, Charles E. Sasser, J. Mason Harris, Molly K. Reif, Rodrigo Diaz, and Gabe Giffin

PURPOSE: Satellite remote sensing of wetlands provides many advantages to traditional monitoring and mapping methods. However, remote sensing often remains reliant on labor- and resource- intensive ground truth data for wetland vegetation identification through image classification training and accuracy assessments. Therefore, this study sought to evaluate the use of unmanned aircraft system (UAS) data as an alternative or supplement to traditional ground truthing techniques in support of remote sensing for identifying and mapping wetland vegetation.

INTRODUCTION: Landscape ecology often involves the identification, quantification, and tracking of system processes (for example, drivers and pressures) and their impacts on feature response and landscape patterns (Elliott et al. 2007, 349). Specific to US Army Corps of Engineers (USACE) missions, civil works project planning, design, and monitoring often requires the identification of habitats and landscape features. Since evaluating ecological processes and patterns requires data from broad spatial extents that cannot easily be collected using field-based methods, researchers are increasingly using remote sensing to provide the data and techniques necessary to classify and detail the distribution, variability, and resiliency of landscape features (Kerr and Ostrovsky 2003; Li et al. 2014).

Remotely sensed imagery and classification approaches can find spectral, textural, shape, and other characteristics unique to individual target types (that is, vegetation type), depending on the spatial and spectral resolution of the imagery used in the analysis. The major steps associated with remote sensing classification to identify wetland vegetation include the following:

1. Image acquisition and preprocessing

2. Selection of training sites and collection of training samples (that is, ground truthing)

3. Selection of an appropriate classifier (that is, algorithm)

4. Feature extraction

5. Post-classification processing

6. Accuracy assessment (German 2014).

Image acquisition and preprocessing involves the collection of remotely sensed data, which must undergo a preparatory preprocessing phase to improve image quality prior to further analysis (Campbell and Wynne 2011, 305). These preparatory steps include radiometric calibration (transformation of digital numbers to physical radiance or reflectance units), atmospheric correction (accounting for atmospheric scattering and absorption), and geometric correction (correcting distortions) (Schott 2007, 57). A suitable classification system is also a prerequisite for a successful classification (Lu and Weng 2007, 824). A classifier should be selected according to 
the overall needs, image spatial resolution, classifier availability, and time constraints (Lu and Weng 2007, 824). Feature extraction, a technique used to extract the essential elements of an image, removes the noise and errors from the original data and reduces the number of spectral bands required for analysis, thereby reducing computational demands and increasing classification accuracy (Campbell and Wynne 2011, 316). The post-classification processing and accuracy assessments typically consist of qualitative and quantitative assessments of the preliminary classification data. The post-processing techniques usually consist of filtering and manual editing to correct misclassified pixels. Accuracy assessments typically use traditional error matrix methods using validation sites selected from field data (Jollineau and Howarth 2008, 3618).

Although each of these remote sensing classification components can provide its own set of unique challenges, one primary challenge is the collection of training samples, also referred to as ground truthing. In remote sensing, ground truth refers to the traditional on-site gathering of reference data and information that characterize states, conditions, and parameters associated with the Earth's surface (Short 1999, 13-1). These ground truth data represent critical components of wetland classifications because they are necessary for training supervised classification algorithms, validating classified areas, and performing error evaluations (Jensen 2015, 500). Most remote sensing classifiers rely on the statistical distributions of the reflectance values of the target classes as defined by the training (ground truth) data provided for each class (Broussard, Suir, and Visser 2018). However, the traditional collection of ground truth information can be cost and labor limiting, often resulting in insufficient representation of target features and conditions (Schowengerdt 2007; Wich and Koh 2018). This limitation can prove problematic, since classification performance depends strongly on the amount and distribution of representative training samples (Tuia, Persello, and Bruzzone 2016, 41).

Several alternatives to traditional field-based ground truthing methods have been used successfully. These alternatives include using existing maps or data to find representative areas for each target class (for example, land cover or National Wetlands Inventory data), using aerial photographs to identify target features (for example, delineating coastline from high-resolution imagery), and using manned aircrafts to observe and record details related to critical landscape features (for example, performing visual vegetation survey from a hovering helicopter) (Alesheikh, Ghorbanali, and Nouri 2007; Neldner and Clarkson 1995; Sasser et al. 2008; Schowengerdt 2007). A novel and relatively untested surrogate for ground truth data is the use of UAS-captured imagery to identify targets or class training samples (Szantoi et al. 2017, 2). UAS-collected data provide many advantages over in situ and other air- and space-borne collections. These advantages include the ability to survey larger and more difficult to access areas, better spatial resolution imagery and video, and the potential for more frequent collections. This application, recently termed drone truthing, could conceptually provide drone-derived training data with increased quantity and distribution for classifying and evaluating other air- and space-borne imagery (Smith 2010; Wich and Koh 2018).

This study sought to evaluate UAS-based drone truth data as a surrogate to traditional ground truth methods. Specifically, the study compared drone-based vegetation identification to traditional field-collected data in coastal Louisiana wetlands, then assessed the accuracy and feasibility of using drone truth training data in conjunction with other air- and space-borne imagery for future landscape and species level classifications. 


\section{METHODS}

Study Area. This study was conducted in the Sabine National Wildlife Refuge (SNWR) and the Mississippi River Delta (MRD) (Figure 1). The SNWR primarily consists of brackish wetlands located west of the Calcasieu Ship Channel near Hackberry, Louisiana. This area experienced significant conversion from wetlands to open water between 1956 and 1978 because of hurricane impacts and altered hydrologic and salinity regimes (Miller 2014, 1). A shift from intermediateand fresh-dominated marsh species to more brackish species also occurred, between 1968 and 1988 (Miller 2014, 1). Since 2002, wetland restoration measures (Calcasieu/Sabine-28 (CS-28) construction from 2002 to 2015) were implemented "as part of the Coastal Wetland Planning, Protection, and Restoration Act (CWPPRA) to provide direct and indirect structural and functional benefits within the [SNWR] and surrounding wetlands" (Suir, Sasser, and Harris 2020, 2644). The CS-28 project consisted of separate creation (cycles) and reference areas ranging in size from $51 \mathrm{ha}^{1}$ to 93 ha within an open-water area of approximately 1,153 ha (Figure 1).

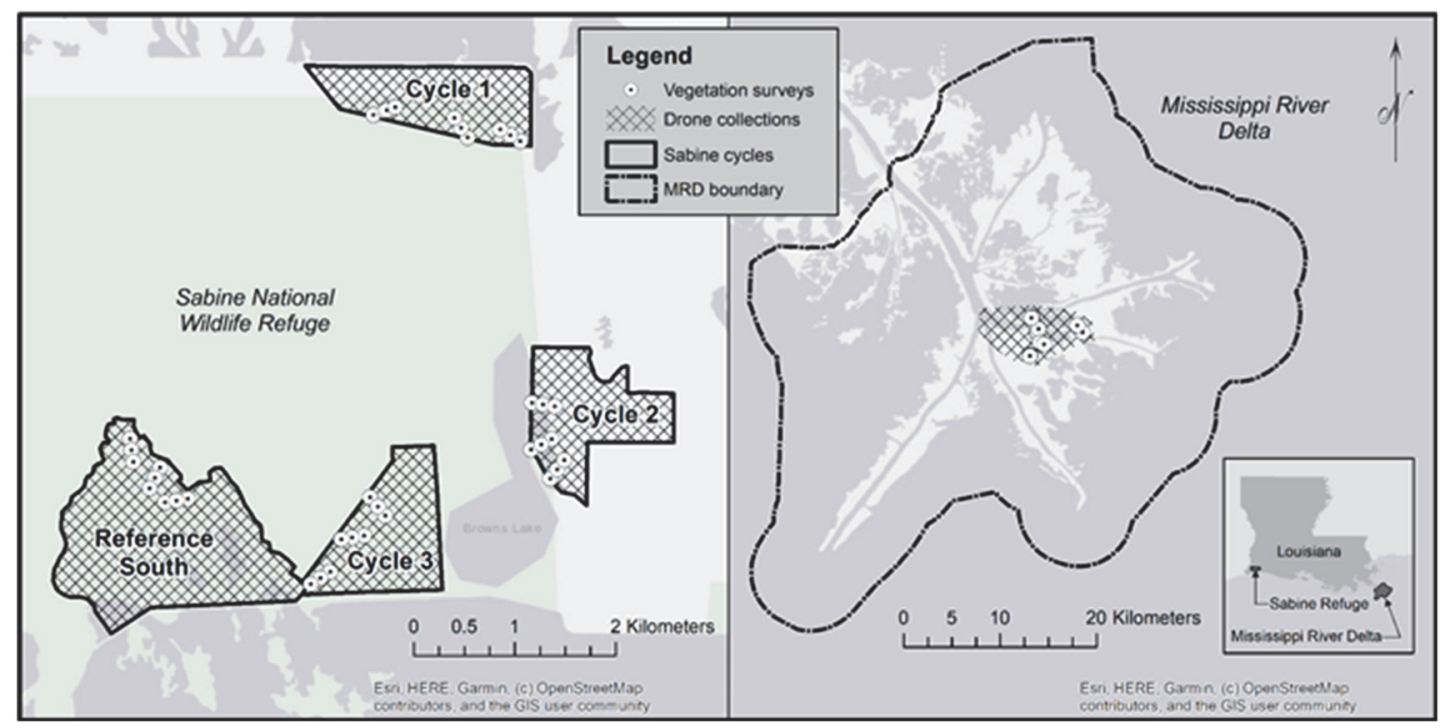

Figure 1. Location map of paired vegetation survey and unmanned aircraft system (UAS) collection points within the Sabine National Wildlife Refuge (SNWR) and the Mississippi River Delta (MRD) study areas.

The MRD (also known as the Plaquemines-Balize Delta) consists of all land and shallow estuarine areas between the two northernmost passes of the Mississippi River and the Gulf of Mexico (Louisiana Coastal Wetlands Conservation and Restoration Task Force 1993, 12) (Figure 1). The MRD, which consists of approximately $300 \mathrm{~km} 2$ of wetlands (Couvillion et al. 2017, 5), provides critical ecosystem services, ranging from regulating (that is, storm, flood, and drought), supporting (that is, soil formation and nutrient cycling), to provisioning services (that is, food and freshwater) (Mendelssohn et al. 2012, 562; Suir 2018, 106). The MRD has experienced dramatic loss of wetlands and significant reductions in ecosystem goods and services over the last half century

\footnotetext{
${ }^{1}$ For a full list of the spelled-out forms of the units of measure used in this document, please refer to US Government Publishing Office Style Manual, 31st ed. (Washington, DC: US Government Publishing Office, 2016), 248-52, https://www.govinfo.gov/content/pkg/GPO-STYLEMANUAL-2016/pdf/GPO-STYLEMANUAL-2016.pdf.
} 
(Day et al. 2000; Couvillion et al. 2011; Suir et al. 2014) and has recently suffered marked dieoffs of critical and stabilizing Phragmites australis (Knight et al. 2018; Suir, Saltus, and Reif 2018).

Field collections of vegetation data. Most remote sensing classifiers rely on the statistical distributions of the reflectance values of the target classes as defined by the training (on-theground) data provided for each class (Carle 2013, 17). This study used an onscreen ocular identification of plant species using UAS-collected video and imagery and compared the results of that exercise to ground truth vegetation survey data. The field collections of vegetation data consisted of existing CWPPRA, Coastwide Reference Monitoring System (CRMS), and Louisiana Coastwide Vegetation Survey data as well as newly collected data from Louisiana State University (LSU) and University of Louisiana-Lafayette (UL-L) researchers (Table 1).

Table 1. Specifications of ground-collected data in the SNWR and MRD study areas. (LSU: Louisiana State University; UL-L: University of Louisiana-Lafayette)

\begin{tabular}{|l||l|l|l|l|l||}
\hline \hline Data & System & Sensor & Source & Date & Location \\
\hline $\begin{array}{l}\text { Vegetation } \\
\text { Composition }\end{array}$ & $\begin{array}{l}\text { Braun-Blanquet } \\
\text { scale }\end{array}$ & Ocular & UL-L & June-July 2019 & SNWR \\
\hline $\begin{array}{l}\text { Vegetation } \\
\text { Composition }\end{array}$ & Composition & Ocular & LSU & 2017 to 2019 & MRD \\
\hline $\begin{array}{l}\text { Vegetation } \\
\text { Composition }\end{array}$ & $\begin{array}{l}\text { Braun-Blanquet } \\
\text { scale }\end{array}$ & Ocular & CRMS & Annual since 2006 & MRD/SNWR \\
\hline $\begin{array}{l}\text { Vegetation } \\
\text { Composition }\end{array}$ & $\begin{array}{l}\text { Braun-Blanquet } \\
\text { scale }\end{array}$ & Ocular & CWPPRA & Annual & MRD/SNWR \\
\hline $\begin{array}{l}\text { Vegetation } \\
\text { Composition }\end{array}$ & $\begin{array}{l}\text { Braun-Blanquet } \\
\text { scale }\end{array}$ & Ocular & $\begin{array}{l}\text { Coastal Vegetation } \\
\text { Survey }\end{array}$ & 2013 & MRD/SNWR \\
\hline
\end{tabular}

The monitoring components of CRMS and CWPPRA consist of a network of monitoring sites in coastal Louisiana used to collect, process, and analyze pedologic (i.e., surface elevation), spatial (i.e., land cover), hydrologic (i.e., salinity), and vegetative (i.e., species cover) data for characterizing coastal wetland landscapes inside and outside of CWPPRA projects (Louisiana Coastal Wetlands Planning Protection and Restoration News, 2018, 3). These programs collect vegetation species composition, relative abundance, and aboveground biomass data (Steyer and Stewart 1992). The Louisiana Coastwide Vegetation Surveys consist of standardized vegetation surveys that document species composition, abundance, and corresponding marsh type (that is, fresh, intermediate, brackish, or saline) (Visser et al. 1998). These surveys use transects oriented in a north-south direction ( $3 \mathrm{~km}$ spacing), with sampling sites located at $0.8 \mathrm{~km}$ spacing along each transect (Sasser et al. 2014). For new data collections, vegetation species composition and percent cover were collected from within $2 \times 2 \mathrm{~m}$ quadrats at each project sample site during periods of peak biomass (Figures 1 and 2C). A team of researchers from the LSU Department of Entomology collected species composition data for monoculture stands in the MRD project site from 2017 to 2019. Likewise, researchers from the UL-L Department of Biology performed vegetation surveys within the SNWR project sites in 2019.

UAS-based imagery and video collections. UAS data in the MRD were collected on multiple dates (August 2015 and June 2016, Louisiana Department of Wildlife and Fisheries 
[LDWF]; February 2018, LSU), using different UAS airframes and sensors (Table 2). The LDWF UAS collections, which consisted of oblique photographs and video, were conducted in the Passa-Loutre Wildlife Management Area in preparation for a 30-year commemorative event related to crevasses created in 1986. The flights were conducted using a multirotor quadcopter (DJI Phantom 3 Advanced) designed for commercial purposes related to aerial video. The flights were conducted June 16-17, 2016, in various areas of the refuge. Typical flight times ranged from 20-25 min, never exceeding a height of $122 \mathrm{~m}$. The airframe was equipped with a Sony-made 12-megapixel 1/2.3-inch Complementary Metal-Oxide Semiconductor sensor behind a f2.8 $20 \mathrm{~mm}$ lens (35mm equivalent), creating a $94^{\circ}$ field of view. Video was captured primarily at $1080 \mathrm{p}(1920 \times 1080)$ at 30 frames per second. The flights were conducted at various heights, and no specific flight plans or transects were in place. The purposes of the flights were cinematic and to highlight the vegetative growth and sediment dispersal that occurred over the last 30 years.

LSU collected UAS imagery within the MRD using a DJI Phantom drone equipped with a lowcost Sentera Single Sensor capable of capturing images in the $575 \mathrm{~nm}$ to $1050 \mathrm{~nm}$ wavelengths (for example, green to near-infrared [NIR]) of the electromagnetic spectrum. AgVault data management software was used for autonomous flight control, image acquisition, and mosaicking of acquired images. Images of the study area were acquired on cloudless days at a flight altitude of $90 \mathrm{~m}$ with 80\% image overlap (frontlap and sidelap) (Sartain, Fleming, and Mudge 2019, 18).

UL-L conducted UAS collections in the SNWR study area using a multirotor platform (Yuneec H520). The flights, which coincided with the SNWR vegetation surveys, occurred in June and July of 2019. The flight area, time, altitude, and duration were configured using the internal autopilot flight planning software DataPilot. The internal GPS module geotagged all images with an initial accuracy of $5 \mathrm{~m}$ horizontal and $8 \mathrm{~m}$ vertical. The hover accuracy of the aircraft was $1.5 \mathrm{~m}$ horizontal and $0.5 \mathrm{~m}$ vertical. The typical flight times ranged 15-23 min. The airframe was equipped with a Yuneec E90 RGB camera with a $23 \mathrm{~mm}$ lens and a diagonal field of view of $91^{\circ}$. Photo resolution was 3:2 $(5472 \times 3648)$, and effective pixels were 20 megapixels. All flights were conducted at $68 \mathrm{~m}$ altitude above ground level using consecutive transects to cover the survey areas with an image overlap of $80 \%$ (frontlap and sidelap). This altitude was chosen to maximize field of view while achieving $<2.5 \mathrm{~cm}$ ground sample distance (GSD) or pixel resolution in the final maps for a precise analysis of vegetation classes and to minimize possible blurred portions (Broussard, Suir, and Visser 2018).

\begin{tabular}{||l|l|l|l||l||l||l||l|||}
\hline \multicolumn{2}{||c|}{ Table 2. Specifications of UAS collected data in the SNWR and MRD study areas. } \\
\hline \hline
\end{tabular}


Image interpretation of vegetation. Image interpretation is the process of visually examining an aerial photograph or digital remote sensing image or video and manually identifying target features within the image (Aber et al. 2019, 163; The Landscape Toolbox 2020). The interpretation process is based on inherent elements within an image, along with prior knowledge - such as vegetation zone, seasonality, and anthropogenic activities or impacts - to differentiate landscape features (Zhao et al. 2014, 4800). These knowledge elements (for example, plant height and color variations) and image attributes (that is, size, shape, tone, texture, shadow, association, and pattern) are especially important for interpretation of wetland vegetation (Aber et al. 2019, 163; Suir et al. 2014, 6; Zhao et al. 2014, 4800).

This study consisted of a blind experiment using field-based survey collections and drone-based image interpretations to identify dominant plant species at matching sample sites but without knowledge from the other method. The image interpretation method used a heads-up, on-screen identification of dominant wetland plants at designated survey locations ( $2 \times 2 \mathrm{~m}$ quadrats $)$ within UAS-collected video (MRD) and derived orthomosaic areas (MRD and SNWR sites). A wetland plant expert performed image interpretations of dominant plants at each collection site. These interpretations were performed without knowledge of the ground truth survey results. The $2 \times 2$ meter quadrats (for example, red square in figure 2, panel C), established for and during the ground truth vegetation surveys, were used as bounding areas for the heads-up onscreen interpretations.

Statistical analysis. Traditionally, remote sensing accuracy assessments consist of statistical analyses to evaluate the accuracy of a classified image using ground truth verification data. However, for this study the statistical assessments instead evaluated the accuracy of the dronebased vegetation identifications as compared to the standard ground truth data. To accomplish this task, the ArcGIS Desktop v10.7.1 Confusion Matrix tool computed user and producer accuracies, derived a Cohen's Kappa statistic for measuring agreement, and generated an overall accuracy score. For this study, the producer's accuracy assessed the probability (individual class accuracies) that real features on the ground were correctly identified using the drone truth techniques. The user's accuracy, or reliability, assessed the probability (individual class accuracies) that features identified using the drone-based image interpretation were present on the ground (per ground truth data). The Cohen Kappa measured the interrater agreement for categorical scales (Boslaugh 2012, 11). The Kappa value ranges from -1 to 1 , and although there are no absolute standards for judging Kappa values, Landis and Koch $(1977,372)$ provide accepted guidelines: $<0$ poor; $0-0.20$ slight; 0.21-0.40 fair; 0.41-0.60 moderate; $0.61-0.81$ substantial; $0.81-1.0$ almost perfect. The overall accuracy, expressed as a percentage, evaluated the proportion of all ground truth classes that were correctly classified using the drone truth interpretations.

RESULTS AND DISCUSSION: This study used a total of 52 paired collection stations: 37 in the SNWR study area and 15 in the MRD. There were seven dominant plant species identified: Distichlis spicata, Phragmites australis, Sagittaria lancifolia, Schoenoplectus robustus, Spartina alterniflora, Spartina patens, and Zizaniopsis miliacea (Table 3). Although water features were not included in the assessments, bare ground was, and provides the eighth and final class. The dominant feature percent cover ranged from $20 \%$ (bare ground, with larger percentage of water) for a collection site in SNWR Cycle 2 to $99 \%$ (Distichlis spicata) for a site in SNWR Cycle 1. The average cover value for dominant feature for all sites was $62.3 \%$. 
Figure 2 shows examples of UAS-collected video and orthophotos from the MRD (panels A and B) and SNWR sites (panel C). Panels A and B are video captures that illustrate the differences in image attributes (that is, size, shape, tone, texture, shadow, association, and pattern) between various dominant plants in the MRD. In panels $\mathrm{A}$ and $\mathrm{B}$, there are discernable differences in the texture, tone, and pattern associated with Phragmites australis and nearby floating aquatic and woody vegetation. Similarly, in panel C (SNWR Cycle 3 orthophoto mosaic; 28 June 2019, $2.5 \mathrm{~cm}$, UL-L) there are discernable differences between the wind-blown or lodged feathery and lightertoned Spartina patens (central and southern portions of panel C) and the darker and more rigid texture of the Spartina alterniflora (northern periphery of panel C).

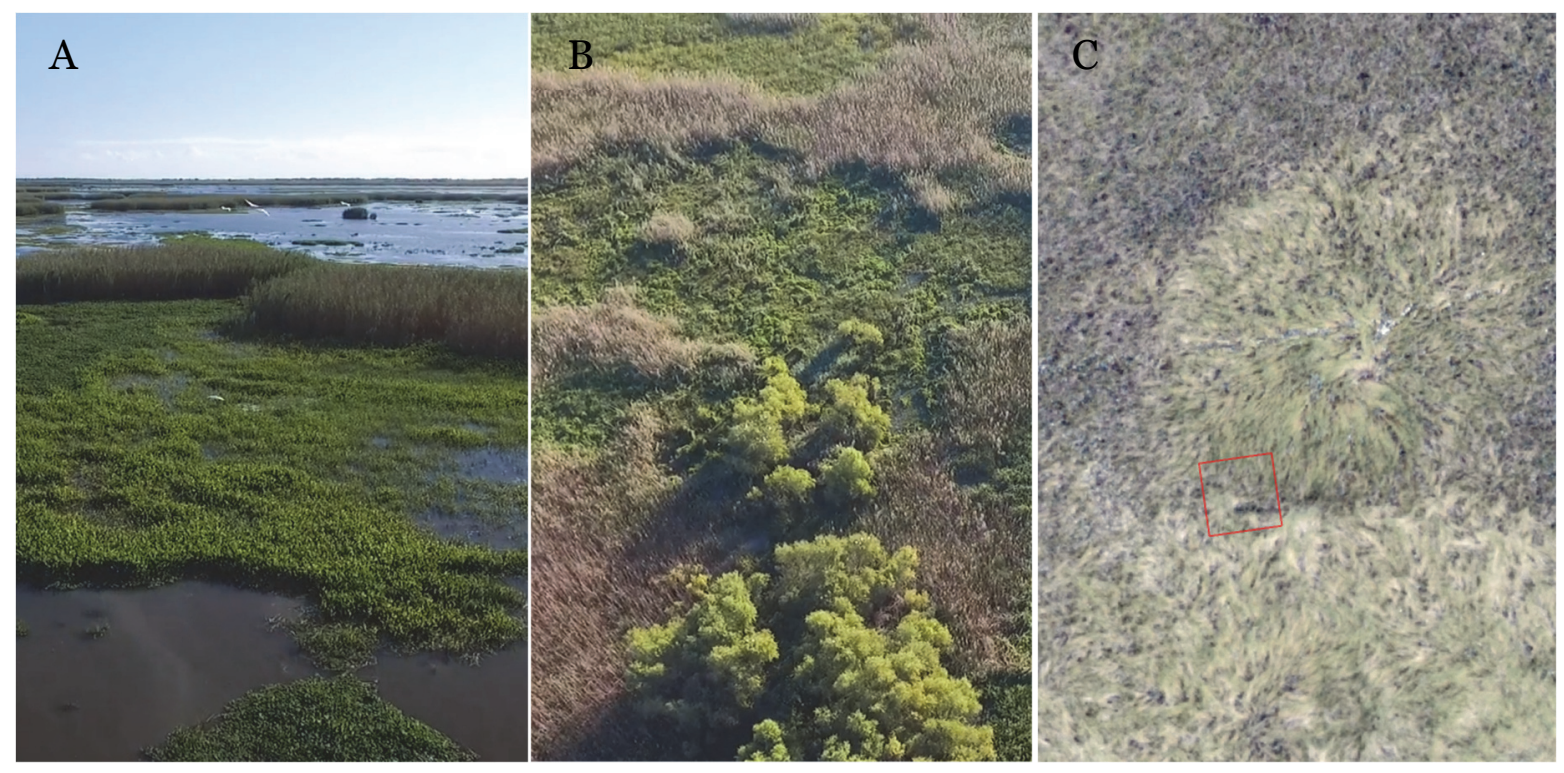

Figure 2. Examples of wetland features and plant species that are discernable using UAS-collected video (panels A and B, MRD) and orthophotos (panel C, Sabine).

To evaluate the accuracy of the UAS collections and interpretations, a confusion matrix was constructed to compare the ground and drone truth results. Table 3 shows the confusion matrix containing each of the eight classes, with Kappa and overall accuracy of the drone truth results. The user accuracies ranged from 50\% (bare ground) to 100\% (Distichlis spicata, Phragmites australis, and Zizaniopsis miliacea), while the producer accuracies ranged from $0 \%$ (Schoenoplectus robustus) to 100\% (bare ground, Spartina patens, Zizaniopsis miliacea).

These sites consisted largely of three dominant plant species, Phragmites australis, Spartina alterniflora, and Spartina patens, which combined accounted for $85 \%$ of the species present at all survey stations. The user and producer accuracies of those three species ranged from $87.5 \%$ (user accuracy for Spartina patens) to 100\% (user and producer accuracy for Phragmites australis and Spartina patens, respectively). Other plant species had a limited number of samples, which can affect accuracies. This limitation was observed for Schoenoplectus robustus, which was dominant at only one survey site, but the image interpretation returned a bare ground classification for that quadrat. This discrepancy is potentially due to the high reflectivity of Schoenoplectus robustus in the imagery, giving it similar image attributes to bare ground. Regardless of sample size, when compared to the traditional ground truth method, the drone truth method had an overall accuracy 
of $90.39 \%$ and a Kappa score of 0.873 . The Kappa score falls in the Landis and Koch $(1977,371)$ established almost perfect range of 0.81-1.0.

To evaluate the accuracy of the UAS collections and interpretations, a confusion matrix was constructed to compare the ground and drone truth results. Table 3 shows the confusion matrix containing each of the eight classes, with Kappa and overall accuracy of the drone truth results. The user accuracies ranged from 50\% (bare ground) to 100\% (Distichlis spicata, Phragmites australis, and Zizaniopsis miliacea), while the producer accuracies ranged from $0 \%$ (Schoenoplectus robustus) to 100\% (bare ground, Spartina patens, Zizaniopsis miliacea). 
Table 3. Confusion matrix comparing ground truth to drone truth dominant plant species in the SNWR and MRD study areas.

\begin{tabular}{|c|c|c|c|c|c|c|c|c|c|c|c|c|}
\hline $\begin{array}{l}\text { Class } \\
\text { value }\end{array}$ & $\begin{array}{l}\text { Bare } \\
\text { ground }\end{array}$ & $\begin{array}{l}\text { Distichlis } \\
\text { spicata }\end{array}$ & $\begin{array}{l}\text { Phragmites } \\
\text { australis }\end{array}$ & $\begin{array}{l}\text { Sagittaria } \\
\text { lancifolia }\end{array}$ & $\begin{array}{l}\text { Schoeno } \\
\text { plectus } \\
\text { robustus }\end{array}$ & $\begin{array}{l}\text { Spartina } \\
\text { alterniflora }\end{array}$ & $\begin{array}{l}\text { Spartina } \\
\text { patens }\end{array}$ & $\begin{array}{l}\text { Zizaniopsi } \\
\text { s miliacea }\end{array}$ & $\begin{array}{l}\text { Classification } \\
\text { overall }\end{array}$ & $\begin{array}{l}\text { Producer } \\
\text { accuracy } \\
\text { (precision) }\end{array}$ & $\begin{array}{l}\text { Overall } \\
\text { accuracy } \\
\text { (OA) }\end{array}$ & Kappa \\
\hline Bare ground & 1 & 0 & 0 & 0 & 0 & 0 & 0 & 0 & 1 & $100 \%$ & - & - \\
\hline $\begin{array}{l}\text { Distichlis } \\
\text { spicata }\end{array}$ & 0 & 4 & 0 & 0 & 0 & 1 & 0 & 0 & 6 & $66.67 \%$ & 一 & - \\
\hline $\begin{array}{l}\text { Phragmites } \\
\text { australis }\end{array}$ & 0 & 0 & 13 & 1 & 0 & 0 & 0 & 0 & 14 & $92.86 \%$ & - & - \\
\hline $\begin{array}{l}\text { Sagittaria } \\
\text { lancifolia }\end{array}$ & 0 & 0 & 0 & 0 & 0 & 0 & 0 & 0 & 0 & - & - & - \\
\hline $\begin{array}{l}\text { Schoenoplec } \\
\text { tus robustus }\end{array}$ & 1 & 0 & 0 & 0 & 0 & 0 & 0 & 0 & 1 & $0 \%$ & - & - \\
\hline $\begin{array}{l}\text { Spartina } \\
\text { alterniflora }\end{array}$ & 0 & 0 & 0 & 0 & 0 & 14 & 1 & 0 & 15 & $93.33 \%$ & - & - \\
\hline Spartina & 0 & 0 & 0 & 0 & 0 & 0 & 14 & 0 & 14 & $100 \%$ & - & - \\
\hline $\begin{array}{l}\text { Zizaniopsis } \\
\text { miliacea }\end{array}$ & 0 & 0 & 0 & 0 & 0 & 0 & 0 & 1 & 1 & $100 \%$ & - & - \\
\hline Truth overall & 2 & 4 & 13 & 1 & 0 & 15 & 16 & 1 & 52 & - & - & - \\
\hline $\begin{array}{l}\text { User accur- } \\
\text { acy (recall) }\end{array}$ & $50 \%$ & $100 \%$ & $100 \%$ & $0 \%$ & - & $93.33 \%$ & $87.50 \%$ & $100 \%$ & - & - & - & - \\
\hline $\begin{array}{l}\text { Overall acc- } \\
\text { uracy }(O A)\end{array}$ & - & - & - & - & - & - & - & - & - & - & $90.39 \%$ & - \\
\hline Kappa & - & - & - & - & - & - & - & - & - & - & - & 0.873 \\
\hline
\end{tabular}


These sites consisted largely of three dominant plant species, Phragmites australis, Spartina alterniflora, and Spartina patens, which combined accounted for $85 \%$ of the species present at all survey stations. The user and producer accuracies of those three species ranged from $87.5 \%$ (user accuracy for Spartina patens) to $100 \%$ (user and producer accuracy for Phragmites australis and Spartina patens, respectively). Other plant species had a limited number of samples, which can affect accuracies. This limitation was observed for Schoenoplectus robustus, which was dominant at only one survey site, but the image interpretation returned a bare ground classification for that quadrat. This discrepancy is potentially due to the high reflectivity of Schoenoplectus robustus in the imagery, giving it similar image attributes to bare ground. Regardless of sample size, when compared to the traditional ground truth method, the drone truth method had an overall accuracy of $90.39 \%$ and a Kappa score of 0.873 . The Kappa score falls in the Landis and Koch $(1977,371)$ established almost perfect range of $0.81-1.0$.

CONCLUSIONS: This technical note describes a proof of concept for using UAS collections as an alternative to traditional field-based ground truth data. While drone truthing techniques incur time and costs for UAS data collection, processing, and interpretation, the amount of potential return in terms of number, diversity, and distribution of samples is where drone truthing could provide significant improvements to site assessment and characterization. We assume field-based surveys are the "truth," but the limited number of field sites, access constraints, and sampling design means that, while the discrete samples are assumed to be the highest level of accuracy, the extrapolation of those data across a larger area may not form a comprehensive or accurate representation of a project area. Thus, the increased quantity and extent provided by drone truthing means we have the ability to more accurately identify the plant species, target features, and landscape types across larger areas. This increased capability is important, since "a sufficient number of training samples and their representativeness are critical" for accurate image classifications (Lu and Weng 2007, 825).

The use of drone truthing to establish training data for supervised classification of wetlands and other critical vegetation communities could be of significant importance to USACE Civil Works restoration and monitoring efforts. The ability to collect a higher volume and distribution of diverse samples could result in more efficient and accurate monitoring and quantification of wetland ecosystem structure and function. An example of potential drone-truthing applications is in remote areas, like the Phragmites australis research conducted in the MRD (Suir, Saltus, and Reif 2018), which presents limited access and requires high labor because of dense vegetation in expansive wetlands. Another study that could have benefited from drone-truthing applications is the recent use of hyperspectral airborne imagery to classify wetland zones in 24 extensive wetlands along coastal Lake Ontario (Suir, Wilcox, and Reif accepted June 2021). Like many studies involving image classification of vegetation, this study used vegetation survey data from an established monitoring program; however, those data were limited to predetermined transects that did not fully represent the composition and distribution of plants within the study sites.

This proof of concept used existing and ongoing data collections to evaluate drone truthing as an alternative to traditional ground truthing methods in relatively simple monoculture stands of wetland vegetation. Future research should consider study designs and data collections for the exclusive purpose of comparing ground- and drone-truthed methods. These focused studies could further evaluate the potential advantages that drone truth data have over traditional ground-based collections. These studies should also evaluate drone truth methods and results in more complex 
wetland landscapes. For example, in fresher systems with a more moderate mix of plant species (Johnson, Sasser, and Gosselink 1985; Suir and Sasser 2017). Additionally, future research should compare image-based classification accuracies using ground truth versus drone truth data. These advancements will help researchers better understand the level of impact that drone truthing data can have on remote sensing analysis methods. They could also help shift to machine learning algorithms and more automated processes that require a lot of training samples (which many remote sensing projects cannot accommodate because of the limited number of ground samples) (Khan and Al-Mulla 2019, 51). This further research could also potentially help overcome the issues associated with limited samples for rare or underrepresented plant species, as observed with this study's Schoenoplectus robustus-dominated site. Ultimately, drone truthing has the potential to overcome some of the major limitations related to on-the-ground, field-collected training data.

ACKNOWLEDGEMENTS: Research presented in this technical note was developed under the Aquatic Plant Control Research Program (APCRP). The USACE Proponent for the APCR Program is Mr. Jeremy Crossland and the Technical Director is Dr. Jennifer Seiter-Moser.

The UAS and flight parameter details in the methods section of this report have been reprinted from Food Webs, 25, James A. Nelson, J. Mason Harris, Justin S. Lesser, W. Ryan James, Glenn M. Suir, and Whitney P. Broussard III, "New Mapping Metrics to Test Functional Response of Food Webs to Coastal Restoration," e00179, Copyright 2020, with permission from Elsevier. https://doi.org/10.1016/j.fooweb.2020.e00179.

POINTS OF CONTACT: For additional information, contact the author, Dr. Glenn M. Suir (225368-5749) Glenn.M.Suir@usace.army.mil, or the acting manager of the Aquatic Plant Control Research Program, Mr. Michael Greer (716-879-4229) Michael.J.Greer@usace.army.mil.

This technical note should be cited as follows:

Suir, Glenn M., Christina L. Saltus, Charles E. Sasser, J. Mason Harris, Molly K. Reif, Rodrigo Diaz, and Gabe Giffin. 2021. Evaluating Drone Truthing as an Alternative to Ground Truthing: An Example with Wetland Plant Identification. APCRP Technical Notes Collection. ERDC/TN APCRP-MI-9. Vicksburg, MS: US Army Engineer Research and Development Center.

\section{REFERENCES}

Aber, James S., Irene Marzolff; Johannes B. Ries; Susan E.W. Aber. 2019. "Visual Image Interpretation" (Chapter 10). In Small-Format Aerial Photography and UAS Imagery: Principles, Techniques and Geoscience Applications, Second edition. Academic Press. DOI: https://doi.org/10.1016/B978-0-12-812942-5.00010-0

Alesheikh, Ali Ashgar, Amir Ghorbanali; N. Nouri. 2007. "Coastline Change Detection Using Remote Sensing." International Journal of Environmental Science \& Technology 4(1):61-66.

Boslaugh, Sarah. 2012. Statistics in a Nutshell: A Desktop Quick Reference. Second Edition. Sebastopol, CA: O'Reilly Media, Inc.

Broussard, Whitney P., Glenn M. Suir, and Jenneke M. Visser. 2018. "Unmanned Aircraft Systems (UAS) and Satellite Imagery Collections in a Coastal Intermediate Marsh to Determine the Land-Water Interface, Vegetation Types, and Normalized Difference Vegetation Index (NDVI) Values." ERDC/TN WRAP-18-1. Vicksburg, MS: US Army Engineer Research and Development Center. DOI: https://hdl.handle.net/11681/29517 
Campbell, James B., and Randolph H. Wynne. 2011. Introduction to Remote Sensing. 5th Edition. New York, NY: Guilford Press.

Carle, Melissa M., 2013. "Spatial structure and dynamics of the plant communities in a pro-grading river delta : Wax Lake Delta, Atchafalaya Bay, Louisiana." LSU Doctoral Dissertations. 73. https://digitalcommons.lsu.edu/gradschool_dissertations/73

Couvillion, Brady R., John A. Barras, Gregory D. Steyer, William Sleavin, Michelle Fischer, Holly Beck, Nadine Trahan, Brad Griffin, and David Heckman. 2011. Land Area Change in Coastal Louisiana (1932 to 2010) Map NO. 3164. Reston, VA: US Geological Survey. https://pubs.usgs.gov/sim/3164/

Couvillion, Brady R., Holly Beck, Donald Schoolmaster, and Michelle Fischer. 2017. Land area change in coastal Louisiana (1932 to 2016) Map No. 3381. Reston, VA: US Geological Survey. https://doi.org/10.3133/sim3381.

Day, John W., Louis D. Britsch, Suzanne R. Hawes, Gary P. Shaffer, Denise J. Reed, and Donald Cahoon. 2000. "Pattern and Process of Land Loss in the Mississippi Delta: A Spatial and Temporal Analysis of Wetland Habitat Change." Estuaries 23(4):425-438. DOI: https://doi.org/10.2307/1353136

Elliott, Michael, Daryl Burdon, Krystal L. Hemingway, Sabine E.Apitz. 2007. Estuarine, Coastal and Marine Ecosystem Restoration: Confusing Management and Science-A Revision of Concepts. Estuarine, Coastal and Shelf Science 74(3):349-366. DOI: https://doi.org/10.1016/j.ecss.2007.05.034

German, Alba. 2014. "Remote Sensing Classification. Algorithms Analysis Applied to Land Cover Change." in Master in Emergency Early Warning and Response Space Application. Mario Gulich Institute.

Jensen, John R. 2015. Introductory Digital Image Processing: A Remote Sensing Perspective. $4^{\text {th }}$ Edition. Glenview, IL: Pearson Education, Inc.

Johnson, W.B., Charles E. Sasser, and James G. Gosselink. 1985. "Succession of Vegetation in an Evolving River Delta, Atchafalaya Bay, Louisiana.” The Journal of Ecology 73(3):973-986. DOI: doi:10.2307/2260162

Jollineau, Marilyne Y. and Philip J. Howarth. 2008. Mapping an inland wetland complex using hyperspectral imagery." International Journal of Remote Sensing 29(12): 3609-3631, DOI: 10.1080/01431160701469099

Kerr, Jeremy T., and Marsha Ostrovsky. 2003. From space to species: ecological applications for remote sensing. Trends in ecology \& evolution, 18(6), pp.299-305. DOI: https://doi.org/10.1016/S0169-5347(03)00071-5

Khan, Asharul Islam, and Yaseen Al-Mulla. 2019. "Unmanned Aerial Vehicle in the Machine Learning Environment." Procedia Computer Science 160:46-53. DOI: https://doi.org/10.1016/j.procs.2019.09.442

Knight, Ian A., Blake E. Wilson, Madeline Gill, Leslie Aviles, James T. Cronin, John A. Nyman, Scott A. Schneider and Rodrigo Diaz. 2018. "Invasion of Nipponaclerda biwakoensis (Hemiptera: Aclerdidae) and Phragmites australis Die-back in Southern Louisiana, USA.” Biological Invasions 20(10):2739-2744. DOI: https://doi.org/10.1007/s10530-018-1749-5. DOI: https://doi.org/10.2307/2529786

Landis, J.Richard, and Gary G. Koch. 1977. "An Application of Hierarchical Kappa-Type Statistics in the Assessment of Majority Agreement Among Multiple Observers.” Biometrics 33(2):363-374.

Li, Miao, Shuying Zang, Bing Zhang, Shanshan Li, and Changshan Wu. 2014. A Review of Remote Sensing Image Classification Techniques: The Role of Spatio-contextual Information. European Journal of Remote Sensing 47(1):389-411. DOI: https://doi.org/10.5721/EuJRS20144723

Louisiana Coastal Wetlands Conservation and Restoration Task Force. 1993. Louisiana Coastal Wetlands Restoration Plan, Main Report and Environmental Impact Statement. URL: https://www.doi.gov/sites/ doi.gov/files/migrated/deepwaterhorizon/adminrecord/upload/Louisiana-Coastal-Wetlands-Conservation-andRestoration-Task-Force-Louisiana-Coastal-Wetlands-Restoration-Plan-Main-Report-And-EIS-Nov-1993.pdf

Louisiana Coastal Wetlands Conservation and Restoration Task Force. 2018. WaterMarks: Louisiana coastal wetlands planning, protection and restoration news. U.S. Army Corps of Engineers, New Orleans District, Public Affairs Office. 58, 54p. 
Lu, Dengsheng, and Qihao Weng. 2007. “A Survey of Image Classification Methods and Techniques for Improving Classification Performance.” International Journal of Remote Sensing 28(5):823-870. DOI: https://doi.org/10.1080/01431160600746456

Mendelssohn, Irving A., Gary L. Andersen, Donald M. Baltz, Rex H. Caffey, Kevin R. Carman, John W. Fleeger, Samantha B. Joye, Qianxin Lin, Edward Maltby, Edward B. Overton, Lawrence P. Rozas. 2012. "Oil Impacts on Coastal Wetlands: Implications for the Mississippi River Delta Ecosystem after the Deepwater Horizon Oil Spill.” BioScience 62(6): 562-574. DOI: https://doi.org/10.1525/bio.2012.62.6.7

Miller, Mike. 2014. "2014 Operations, Maintenance, and Monitoring Report for Sabine Refuge Marsh Creation, CS-28." (Prepared by Mike Miller). Lafayette, Louisiana: State of Louisiana, Coastal Protection and Restoration Authority of Louisiana, Office of Coastal Protection and Restoration. URL: https://www.lacoast.gov/reports/project/CS-28_2014_OM\&M_Final.pdf

Neldner, Victor John, and John R. Clarkson. 1995. "Cape York Peninsula Land Use Strategy: Natural Resources Analysis Program: Vegetation Survey and Mapping of Cape York Peninsula." Brisbane, Australia: The State of Queensland and Commonwealth of Australia. URL: https://capeyorknrm.com.au/maps-data/resource/ f0939f6d-5032-4ab1-b020-9994c957bc66

Sartain, Bradley T., Jonathan P. Fleming, and Christopher R. Mudge. 2019. "Utilizing Remote Sensing Technology for Monitoring Chemically Managed Giant Salvinia (Salvinia molesta) Populations." Journal of Aquatic Plant Management 57: 14-22. URL: http://www.apms.org/wp/wp-content/uploads/japm-57-01-14-full.pdf

Sasser, Charles E., Visser, Charles E. Sasser, Jenneke M. Visser, Edmond Mouton, Jeb Linscombe, and Steve B. Hartley. 2008. "Vegetation Types in Coastal Louisiana in 2007. Open-File Report 2008-1224, 1 sheet, scale 1:550,000. Reston, VA: US Geological Survey. URL: https://pubs.usgs.gov/of/2008/1224/

Sasser, Charles E., Jenneke M. Visser, Edmond Mouton, Jeb Linscombe, and Steve B. Hartley. 2014. Vegetation Types in Coastal Louisiana in 2013. Scientific Investigations Map, 3290(1). Reston, VA: US Geological Survey. DOI: $10.3133 / \operatorname{sim} 3290$

Schott, John R. 2007. Remote Sensing: The Image Chain Approach. New York, NY: Oxford University Press Inc.

Schowengerdt, Robert A. 2007. Remote Sensing: Models and Methods for Image Processing, $3^{\text {rd }}$ Edition. Elsevier, Inc. DOI: https://doi.org/10.1016/B978-0-12-369407-2.X5000-1

Short, Nicholas M. 1999. Remote Sensing and Image Interpretation and Analysis. Jon W. Robinson, Ed. Greenbelt, MD: NASA/Goddard Space Flight Center. https://web.archive.org/web/19990224222101/http://rst.gsfc.nasa.gov:80/TofC/toc1.html

Smith, A. 2010. "Image Segmentation Scale Parameter Optimization and Land Cover Classification Using the Random Forest Algorithm.” Journal of Spatial Science 55 (1): 69-79. doi:10.1080/14498596.2010.487851.

Steyer, Gregory D., and Robert E. Stewart, Jr. 1992. "Monitoring Program for Coastal Wetlands Planning, Protection, and Restoration Act Projects." National Wetlands Research Center Open File Report 9341. Washington, DC: US Fish and Wildlife Service.

Suir, Glenn M., William R. Jones, Adrienne L. Garber, and John A. Barras. 2014. "Pictorial Account and Landscape Evolution of the Crevasses near Fort St. Philip, Louisiana." MRG\&P Report No. 2. US Army Corps of Engineers. https://pubs.er.usgs.gov/publication/70094484

Suir, Glenn Michael. 2018. Sediment and Plant Dynamics in a Degrading Coastal Louisiana Landscape. LSU Doctoral Dissertation. 4504. https://digitalcommons.lsu.edu/gradschool_dissertations/4504

Suir, Glenn M., Christina L. Saltus, and Molly K. Reif. 2018. "Geospatial Assessments of Phragmites australis Die-off in South Louisiana: Preliminary Findings.” Aquatic Plant Control Research Program, ERDC/EL TR18-9. Vicksburg, MS: US Army Engineer Research and Development Center.

DOI: https://hdl.handle.net/11681/28998

Suir, Glenn M., and Charles E. Sasser. 2017. Floristic Quality Index of Restored Wetlands in Coastal Louisiana. ERDC/EL TR-17-15. Vicksburg, MS: US Army Engineer Research and Development Center. DOI: https://hdl.handle.net/11681/22930 
Suir, Glenn M., Charles E. Sasser, and John M. Harris. 2020. "Use of Remote Sensing and Field Data to Quantify the Performance and Resilience of Restored Louisiana Wetlands." Wetlands 40, 2643-2658.

https://doi.org/10.1007/s13157-020-01344-y

Suir, Glenn M., Douglas A. Wilcox, and Molly K. Reif. Accepted June 2021. "Classification of Typha-dominated wetlands using airborne hyperspectral imagery along Lake Ontario, USA." Aquatic Ecosystem Health \& Management.

Szantoi, Zoltan, Scot E. Smith, Giovanni Strona, Lian Pin Koh, and Serge A. Wich. 2017. "Unmanned Aerial Vehicles for Environmental Applications." International Journal of Remote Sensing 38(8-10) 2231-2245. DOI: $10.1080 / 01431161.2017 .1280638$

The Landscape Toolbox. (Accessed May 2020/Site last updated in 2014). Image Interpretation. Multiple contributors. Retrieved from: https://wiki.landscapetoolbox.org/doku.php/remote_sensing_methods: image_interpretation

Tuia, Devis, Claudio Persello, and Lorenzo Bruzzone. 2016. "Domain Adaptation for the Classification of Remote Sensing Data: An Overview of Recent Advances." IEEE Geoscience and Remote Sensing Magazine 4(2):4157. DOI: doi: 10.1109/MGRS.2016.2548504

Visser, Jenneke M., Charles E. Sasser, Robert H. Chabreck, and R.G. Linscombe. 1998, Marsh vegetation types of the Mississippi River Deltaic Plain: Estuaries, 21(4B): 818-828.

Wich, Serge A. and Lian Pin Koh. 2018. Conservation Drones: Mapping and Monitoring Biodiversity. New York, NY: Oxford University Press.

Zhao, Yuanyuan., Peng Gong, Le Yu, Luanyun Hu, Xueyan Li, Congcong Li, Haiying Zhang, Yaomin Zheng, Jie Wang, Yongchao Zhao, Qu Cheng, Caixia Liu, Shuang Liu \& Xiaoyi Wang. 2014. "Towards A Common Validation Sample Set for Global Land-Cover Mapping." International Journal of Remote Sensing 35(13):4795-4814. DOI: 10.1080/01431161.2014.930202

NOTE: The contents of this technical note are not to be used for advertising, publication, or promotional purposes. Citation of trade names does not constitute an official endorsement or approval of the use of such products. 